\title{
Amor, masculinidades e resistência: uma leitura queer
}

\author{
Love, masculinities and resistance: a queer reading
}

Amor, masculinidades y resistencia: una lectura queer

Bianca Rosina Mattia*

\section{Resumo}

O estranhamento, o anormal, as diversas expressões de gênero e o abjeto que caracterizam o queer, na medida em que possibilitam novos olhares, sobretudo pela pluralidade de identidades que revelam, desafiam a heteronormatividade, colocam em crise a suposta identidade viril masculina e fazem com que se desconfie das normatividades, das ordens e do que a elas corresponda. Com aporte na teoria queer, a par dessas possibilidades de pensamento, a proposta deste trabalho é apresentar algumas reflexões acerca da experiência amorosa vivida entre os adolescentes Camilo e Cosme, narrada no romance $O$ amor dos homens avulsos, do escritor Victor Heringer, publicado em 2016. A experiência amorosa vivida entre as personagens, quando lida sob a perspectiva do estranhamento queer, mostra-se libertária, ainda que enfrente brutalidades decorrentes dos preconceitos construídos e perpetrados pela lógica heteronormativa. $\mathrm{O}$ amor presente na narrativa é tomado como prática de resistência à hegemonia heterossexual, especialmente em um contexto político opressor, e como combate à masculinidade tóxica, fonte de desumanização.

Palavras-chave: amor, heteronormatividade, literatura, masculinidade tóxica.

\section{Abstract}

The strangeness, the abnormal, the diverse expressions of gender and the abject that characterize queer, insofar as they enable new perspectives, above all because of the plurality of identities that reveal, challenge heteronormativity, put in crisis the supposed masculine virile identity and cause to be suspicious of norms, orders and what corresponds to them. Based on queer theory, alongside these possibilities of thought, the purpose of this paper is to present some reflections on the love experience lived by the adolescents Camilo and Cosme, narrated in the novel $O$ amor dos homens avulsos, by the writer Victor Heringer, published in 2016. The love experience lived between the characters, when read from the perspective of queer strangeness, proves to be libertarian, even though it faces brutalities resulting from the prejudices constructed and perpetrated by the heteronormative logic. The love present in the narrative is taken as a practice of resistance to heterosexual hegemony, especially in an oppressive political context, and as a fight against toxic masculinity, a source of dehumanization.

Keywords: love, heteronormativity, literature, toxic masculinity.

\section{Resumen}

La extrañeza, lo anormal, las diversas expresiones de género y lo abyecto que caracterizan a queer, en la medida en que permiten nuevas perspectivas, sobre todo debido a la pluralidad de identidades que revelan, desafían la heteronormatividad, ponen en crisis la supuesta identidad masculina masculina y causan sospechar de las normas, órdenes y lo que les corresponde. Basado en la teoría queer, junto con estas posibilidades de pensamiento, el propósito de este artículo es presentar algunas reflexiones sobre la experiencia amorosa vivida por los adolescentes Camilo y Cosme, narrada en la novela $O$ amor dos homens avulsos, del escritor Victor Heringer, publicada en 2016. La experiencia amorosa vivida entre los personajes, cuando se lee desde la perspectiva de la extrañeza queer, demuestra ser libertaria, a pesar de que enfrenta brutalidades resultantes de los prejuicios construidos y perpetrados por la lógica heteronormativa. El amor presente en la narrativa se toma como una práctica de resistencia a la hegemonía heterosexual, especialmente en un contexto político opresivo, y como una lucha contra la masculinidad tóxica, una fuente de deshumanización.

Palabras-clave: amor, heteronormatividad, literatura, masculinidad tóxica.

\footnotetext{
* Universidade Federal de Santa Catarina (UFSC), Florianópolis, SC, Brasil. (Dorcid.org/0000-0002-0136-1241. E-mail: biancamattia@gmail.com
} 
Oh vós, homens que andais pelo caminho,

Olhai-me, cercai-me todos, abraçai-me,

Abraçai-me de amor e de amigo, na meiga carícia indecisa,

Cegos, mudos, viris, na imperfeição irremediável!

Publicado em fevereiro de 2019 na revista brasileira Cult, o dossiê "Cartografias da masculinidade" compôs-se de cinco ensaios que encamparam os seguintes eixos temáticos anunciados na capa da edição: fantasmas do mito viril; o colapso da lógica identitária; destinos do masculino; e maneiras plurais de ser homem. Já em sua apresentação, “Do mito aos horizontes de desconstrução", assinada pelo professor Pedro Ambra, doutor em Psicologia Social, ao se lançar a pergunta "O que é o homem?", assinalam-se respostas que dão ensejo às discussões, sobretudo acerca da chamada "crise da masculinidade". De acordo com Ambra (2019), as possíveis respostas "quase sempre se conjugam num imperativo determinado", ou seja, circundadas "a partir de uma lógica do 'dever ser'" (2019, p. 17). Como se constitui a identidade masculina, indaga Ambra, "tendo como tarefa tanto a correspondência ao universal quanto a injunção, tantas vezes ouvida por meninos em tom ameaçador, 'seja homem!'?" (2019, p. 17).

A referida "crise da masculinidade", fundada numa ideia de que a partir da ascensão dos movimentos feministas os homens passaram a não mais saber como ser homens, configura-se num "constructo ideológico [...] que pregava ter havido uma era de ouro onde os homens poderiam ser homens de verdade" (Ambra, 2019, p. 18). A crise estaria fundada a partir do momento em que a possibilidade de viver esse passado viril thes fosse tolhida. Ainda que se constitua em um passado mitológico, as reiteradas menções a esse momento na história no qual imperou uma suposta identidade viril, "produz[em] subjetividades dispostas a sustentar esse ideal vazio na tentativa de não ter de se haver com seus próprios limites e seu futuro incerto" (Ambra, 2019, p. 18). Entre as alternativas propostas por Ambra (2019) no combate à masculinidade tóxica - compreendida como aquela que, na tentativa incessante de resgate do mito viril, produz violências de toda ordem contra os próprios homens - está, além da denúncia, a busca por "compreender como homens representam-se a si mesmos" $(2019$, p. 19). E finaliza ressaltando que cabe ainda perguntar "se a discussão que orbita ao redor dessa representação hegemônica de masculinidade, no singular, pode abarcar e libertar as mais distintas experiências de homens de diferentes vivências eróticas, corporais, de classe e raça" (Ambra, 2019, p. 19).

Se esta última pergunta puder ser entendida como sucessiva e consequencial à alternativa proposta pelo autor, de buscar compreender como os homens representam a si mesmos, então um primeiro e oportuno lugar de estudo talvez esteja no espaço literário. Na literatura, por meio da criação de personagens, o que se revela são as mais diversas experiências humanas, compreendidas estas como constituintes dos sujeitos, ou seja, a representação da experiência não no sentido de algo que pertence ao sujeito, que lhe seja da ordem do ter, mas, sim, como algo que esteja na constituição do seu ser, nos termos do que propõe Joan Scott (1999, p. 27):

não são os indivíduos que têm experiência, mas os sujeitos é que são constituídos através da experiência. A experiência, de acordo com essa definição, torna-se, não a origem de nossa explicação, não a evidência autorizada (porque vista ou sentida) que fundamenta o conhecimento, mas sim aquilo que buscamos explicar, aquilo sobre o qual se produz conhecimento. Pensar a experiência dessa forma é historicizá-la, assim como as identidades que ela produz.

Ao compreender que a experiência constitui subjetividades, Scott (1999) traz para o âmbito do subjetivo as relações sociais e históricas, o que possibilita historicizar a experiência, ou seja, "recusar a separação entre 'experiência' e linguagem e insistir na qualidade produtiva do discurso" (1999, p. 42). A experiência, portanto, não é compreendida como algo inerente ao indivíduo, mas como aquilo que se constrói de forma histórica e social na constituição do sujeito 
e, por isso mesmo, a subjetivação não é estática nem imutável, já que o pessoal se entrelaça com o social. É nesse sentido que Scott também se vale do pensamento de Teresa de Lauretis (1994) acerca da experiência: de acordo com Lauretis, a experiência "se altera e é continuamente reformada, para cada sujeito, através de seu contínuo engajamento na realidade social, uma realidade que inclui [...] as relações sociais de gênero" (Lauretis, 1994. p. 228).

Historicizar a noção de experiência, como propõe Scott (1999), requer a recusa de uma separação entre experiência e linguagem, o que significa pensar que a constituição subjetiva dos sujeitos acontece discursivamente. Nesse sentido,

sujeitos são constituídos discursivamente, mas há conflitos entre sistemas discursivos, contradições dentro de cada um deles, significados múltiplos possíveis para os conceitos que eles utilizam. E sujeitos são, de fato, agentes. Eles não são indivíduos unificados, autônomos, exercendo a vontade livre, mas sim sujeitos cuja atuação é constituída através de situações e status que lhes é conferido (Scott, 1998, p. 320).

O discurso, a par do pensamento de Scott (1998), pode ser compreendido como algo que constitui categorias de gênero, papéis de gênero e dualidades que colocam os indivíduos em lugares determinados. No espaço normativo binário, por exemplo, a experiência vivida por um corpo discursivamente constituído como feminino será diferente da experiência vivida por um corpo discursivamente constituído como masculino. Quando os corpos são categorizados discursivamente como femininos ou masculinos, toda uma série de conceitos é utilizada para fortalecer esta distinção. Isso faz com que esses corpos sejam impelidos a desempenhar funções que são exclusivamente determinadas pelo gênero que lhes é imposto.

Se a construção da subjetividade do sujeito historicizado passa pelas suas experiências, e sendo as experiências produzidas pelos mais diferentes discursos (Scott, 1998), cabe pensar que a literatura também fornece experiências por meio do recurso discursivo. Através da narrativa literária é possível contar as experiências de sujeitos historicizados e, a partir dessas experiências, problematizar as categorias universalizantes de modo a perceber como as identidades são construídas. Não se pode, contudo, esquecer que nenhuma representação é neutra, tampouco o é o discurso que a realiza. Além disso, a criação de personagens como representação de uma vida singular não fica apenas no imaginário de quem as escreve ou de quem as lê, mas influencia, sobretudo, na construção da subjetividade tanto de seus criadores quanto de seus leitores.

Isso porque, retomando a proposta de Scott (1998), como sujeitos historicizados que também somos, de algum modo as representações que são produzidas pelos discursos, inclusive as representações literárias, modelam o sujeito real.

A par disso, este trabalho tem como objetivo tecer algumas reflexões com aporte na teoria queer acerca da possibilidade de rompimento da ordem heteronormativa e combate à masculinidade tóxica pela via da experiência amorosa como prática de resistência. Busco, nesse sentido, a partir do espaço literário, especialmente do romance $O$ amor dos homens avulsos, do escritor carioca Victor Heringer (2016), apresentar uma leitura do amor sob a perspectiva queer.

Publicado em 2016 pelo selo editorial da Companhia das Letras, o romance de Heringer apresenta a história de amor entre os adolescentes Camilo e Cosme, narrada, em sua maior parte, pela voz de Camilo, uma vez que não deixa de ser a história da vida deste personagem a partir do acontecimento de seu primeiro amor. O romance é situado no subúrbio do Rio de Janeiro, no bairro fictício do Queím, e perpassa a década de 1970 e o respectivo cenário do regime ditatorial de então. $\mathrm{O}$ amor vivido entre os adolescentes é interrompido pelo brutal assassinato de Cosme ainda na adolescência, episódio que marcará para sempre a vida de Camilo. A maneira como se deu parte da construção do romance é detalhada pelo autor na nota de agradecimento ao final do livro:

Quando comecei este $O$ amor dos homens avulsos, pedi, publicamente, ajuda dos futuros leitores para escrever um parágrafo do livro. Abri um site na internet em que pedia que me contassem o nome do primeiro amor deles e, se quisessem, os próprios. Bastava preencher um formulário. A lista foi transcrita no romance. [...] É incrível o que as pessoas respondem 
quando você pergunta sobre o amor delas. [...]. Resultou como a quadrilha do Drummond, só que ninguém fica fora da história. Ou todo mundo fica (Heringer, 2016, p. 153-154).

Das pouco mais de 150 páginas do romance, quatro delas são preenchidas com os nomes daqueles que foram primeiramente amados, amadas e amades, numa quadrilha drummondiana sempre intercalada pelo amor de Camilo por Cosmim:

Amei o Cosmim como você amou o seu primeiro amor, que se chamava Bruno ou Pablo ou Ilyich, Ricardo ou Rhana, Luciano, Eduardo, Diego ou Carlos Octávio, Kátia, Mariana, Lucas, Marisa ou Carlos Eduardo, Rafael, Raí ou Solange, ou Luíza, Fabiana, Adolfo, Lígia, Joana, Érica, Mateus. Amei como Lucas amou Sophia e Daniel amou Gabriela. [...] Luciane amou Jefferson e Otávio amou Rui como eu amei Cosmim. Ana amou Rodrigo como eu amei Cosmim. Danilo foi amado por Ana Luíza e Théodore foi amado por Eugénie como fui amado por Cosmim. [...] Daniela amou Ricardo, Thiago amou Natália, Priscila amou Andreas, Diogo amou Luciana, Leonardo amou Ícaro como eu amei Cosmim, pela primeira e única vez. [...] Como Orlando amou Ana e Marta amou Fernando, como Caco amou Bia e Daniel amou Fernanda, Rodrigo amou Douglas e eu amei Cosmim. [...] Como André amou Luca, como Tayana amou Nanda, eu amo Cosmim, o primeiro e o único (Heringer, 2016, p. 69-73, grifo nosso).

Nessa construção textual de frases que se subordinam comparativamente, a história de amor construída por Heringer (2016) quer ser apenas uma história de amor como a de tantas e tantos e tantes, não em um sentido menor, corriqueiro ou banal, mas no sentido de que a única categoria possível seja a do amor, sem as adjetivações da ordem da sexualidade. $\mathrm{O}$ foco da história de amor entre Cosme e Camilo não quer estar na delimitação de um amor entre homossexuais. Como bem ponderou Leandro Soares da Silva (2019, s.p.), "ao contrário de muitas histórias com personagens homossexuais, o desejo proibido não vem junto com a angústia de possuir uma identidade proscrita".

É no amor vivido entre os adolescentes Cosme e Camilo que se opera a possibilidade de pensar uma vivência fora de uma ordem que, mais do que exigir, impõe identidades determinadas. Esta ordem, contudo, não traz consigo qualquer segurança de imutabilidade e estabilidade, a ponto de que a crise da masculinidade, inicialmente aqui delineada, é também compreendida como crise da identidade masculina. Às reflexões apresentadas por Ambra (2019), naquele mesmo dossiê "Cartografias da masculinidade", somam-se as de Eduardo Leal Cunha (2019), que vai além, ao ressaltar que

a suposta crise da identidade masculina poderá ser referida não apenas à nossa dificuldade em lidar com uma ideia de homem que se afasta da natureza e perde suas fronteiras nítidas, mas ao colapso da própria lógica identitária, representada paradoxalmente pelo modo como as identidades e suas fronteiras se multiplicam continuamente, e, assim, tornam-se inevitavelmente instáveis e incapazes de oferecer a segurança ontológica que nos prometiam, ou seja, a certeza de ser quem somos e de nos distinguirmos com clareza de quem e do que não podemos ser (Cunha, 2019, p. 27).

O colapso das identidades emerge da impossibilidade de permanência da ordem normativa heterossexual, ${ }^{1}$ a qual delimita as possibilidades de vida dentro de uma lógica unicamente binária: homem/mulher e, a partir disso, a construção de papéis de gênero que correspondam respectivamente à categoria na qual o sujeito é colocado, de acordo com o sexo biológico. De tal modo que, como destaca Judith Butler, "a formação de um sujeito exige uma identificação com o fantasma normativo do sexo" (2000, p. 154). Isso porque, de acordo com a filósofa, o sexo corresponde a uma categoria normativa, o "ideal regulatório", conforme Michel Foucault (2010), “cuja materialização é imposta [...] através de práticas altamente reguladas" (Butler, 2000, p. 151). Nesse sentido, “[o 'sexo'] não funciona apenas como uma norma, mas é parte de

\footnotetext{
${ }^{1}$ A heterossexualidade compulsória, inicialmente apresentada por Adrienne Rich "como uma instituição política que retira o poder das mulheres" (2010, p. 19), estende-se para a compreensão, de acordo com Richard Miskolci, de "imposição como modelo [de] relações amorosas ou sexuais entre pessoas do sexo oposto. Ela se expressa, frequentemente, de forma indireta, por exemplo, por meio da disseminação escolar, mas também midiática, apenas de imagens de casais heterossexuais. Isso relega à invisibilidade os casais formados por dois homens ou duas mulheres" (2017, p. 47-48).
} 
uma prática regulatória que produz os corpos que governa" (Butler, 2000, p. 151). Contudo - e é aqui que se pode pensar positivamente no colapso das identidades -, Butler (2000) ressalta que,

O fato de que essa reiteração [das convenções de gênero] seja necessária é um sinal de que a materialização não é nunca totalmente completa, que os corpos não se conformam, nunca, completamente, às normas pelas quais sua materialização é imposta. Na verdade, são as instabilidades, as possibilidades de rematerialização, abertas por esse processo, que marcam um domínio no qual a força da lei regulatória pode se voltar contra ela mesma para gerar rearticulações que colocam em questão a força hegemônica daquela mesma lei regulatória (Butler, 2000, p. 152).

No âmbito dessas rearticulações, destaca-se "a política das multidões queer", nas palavras de Paul B. Preciado (2011). Tal política eleva-se "de uma posição crítica a respeito dos efeitos normalizantes e disciplinares de toda formação identitária, de uma desontologização do sujeito da política das identidades: não há uma base natural ("mulher", "gay" etc.) que possa legitimar a ação política" (Preciado, 2011, p. 18). Apesar de se lançarem sobre as identidades não normativas, os estudos de gênero, os queer studies e a teoria queer também abarcaram as identidades normativas, de forma a relativizá-las (Lugarinho, 2012). Dessa forma é que, observa Mário César Lugarinho, "as identidades não normativas põem em causa a validade do conceito de masculinidade hegemônica como um efetivo exercício de uma identidade de gênero" (2012, p. 79). Percebe-se, a partir disso, que a masculinidade hegemônica se aloca dentro de um campo ideal afastada da esfera real, o que the confere uma condição "de instância discursiva do que exatamente a expressão de um indivíduo real" (Lugarinho, 2012, p. 79). A identidade masculina, uma vez confrontada pela teoria queer, coloca-se em estado de crise na medida em que se vê obrigada a rever os papéis, as funções e os estereótipos que lhe foram destinados por forças culturais. O queer faz provocações para pensar a instabilidade, a variabilidade e a mutabilidade das identidades, mas também ao que se impõe como normativo, e o faz escolhendo a via das possibilidades não normativas. Tais provocações podem ser encontradas no âmbito da literatura, pois como bem indaga Ana Luísa Amaral, "não será o poético (no sentido lato do termo) o espaço privilegiado para discutir a não-existência de uma identidade estável e, portanto, a metamorfose, sempre?" (2017, s.p.).

No romance de Heringer, uma das personagens a partir da qual proponho pensar o rompimento da heteronormatividade é Camilo, especialmente durante a sua adolescência. Camilo nasceu e cresceu no bairro do Queím, antiga fazenda de escravos, situado entre Engenho Novo e Andaraí. Apesar de subúrbio, a personagem desfruta de privilégios inacessíveis aos demais moradores do bairro: casa grande, com piscina, empregada e cuidadora. Adolescente, Camilo não sai à rua, não tem amigos e isso porque não consegue andar muito bem: "Tenho a perna fraca. Monoparalisia do membro inferior esquerdo. Aleijado, mas não muito. Aos cinco, já mancava; aos oito, de muletas" (Heringer, 2016, p. 14). A sensação de ser um garoto comum, contudo, ele tinha quando, em férias, abandonava as muletas e passava a usar um cajado de pau de goiabeira: "Assim me sentia selvagem, andarilho ou xamã, garoto comum. (Na maior parte do tempo, eu precisava me agarrar com as duas mãos.) Esse mesmo pedaço de pau hoje me serve de bengala, envelheci apoiado nele" (Heringer, 2016, p. 14). A dificuldade em caminhar era o motivo para que Camilo fosse privado de uma vida livre para além da sua casa e da escola: "Não me deixavam ir brincar na rua. Um garoto aleijado não duraria muito tempo nas mãos da molecada do Queím" (Heringer, 2016, p. 21).

As privações impostas a Camilo pela família repercutem na impossibilidade do início de uma convivência social da personagem que não fosse o ambiente escolar. $\mathrm{O}$ corpo de Camilo não corresponde a um corpo considerado normativamente saudável, o que o faz enfrentar as barreiras culturalmente construídas para impedir sua sociabilidade. Ao retomar os estudos de Michel Foucault (2010) em Os anormais, a situação da personagem de Camilo pode ser lida como uma das figuras que constitui o domínio da anomalia: o indivíduo a ser corrigido e que tem um campo de aparecimento bastante específico: "é a família mesma, o exercício de seu poder interno ou na gestão da sua economia; ou, no máximo, é a família em sua relação com as instituições que lhe são vizinhas ou que a apoiam" (Foucault, 2010, p. 49). O que está em jogo é, sobretudo, a existência de uma norma, de modo que, a ocupação de determinados espaços 
pressupõe uma adequação normativa e, uma vez considerado inadequado, as possibilidades se restringem à correção, a fim de se conformar aos padrões normativos ou à exclusão. Para fazer referência à norma, Foucault (2010) retoma o estudo de Canguilhem, no livro O normal e o patológico, da seguinte forma: "a norma não se define absolutamente como uma lei natural, mas pelo papel de exigência e de coerção que ela é capaz de exercer em relação aos domínios a que se aplica. [...] a norma traz consigo ao mesmo tempo um princípio de qualificação e um princípio de correção" (Foucault, 2010, p. 43). As normas estabelecidas são de comportamento e de existência e são determinadas, diferenciando-se do que é considerado "normal", moralmente e com força imperativa (Spargo, 2017).

No âmbito da sexualidade, a norma, compreendida como heteronormatividade, faz-se presente como o imperativo da heterossexualidade, sendo todas as outras formas de comportamento consideradas desvios dessa norma. Guacira Lopes Louro (2018) expõe didaticamente a lógica heteronormativa e convém citá-la:

Uma lógica heteronormativa rege a sequência que presume que, ao nascer, um corpo deva ser designado como macho ou como fêmea, o que implicará, por conseguinte, assumir o gênero masculino ou feminino e, daí, expressar desejo por alguém de sexo/gênero oposto ao seu. Portanto, um corpo viável, ou melhor, um sujeito pensável está circunscrito aos contornos dessa sequência "normal". Uma vez que a lógica que sustenta esse processo é binária, torna-se insuportável (e impensável) a multiplicidade dos gêneros e das sexualidades. Aqueles e aquelas que escapam da sequência e das normas regulatórias arriscam-se, pois, no domínio da abjeção (Louro, 2018, p. 88-89).

Richard Miskolci (2017) pondera, ainda, que no regime da heteronormatividade, "a sociedade exige o cumprimento das expectativas com relação ao gênero e a um estilo de vida que mantêm a heterossexualidade como um modelo inquestionável para todos/as" (2017, p. 46). O processo de heteronormatividade se faz presente nos mais diversos ambientes e instituições sociais de tal modo que, não apenas os mantém, como também os justifica, no sentido de que, tanto no âmbito privado - na família -, quanto na seara pública - nas instituições de Estado -, segue-se o imperativo de uma construção a partir do modelo do sujeito heterossexual (Louro, 2017). De forma majoritária, o poder masculino sobressai em todos esses espaços, inclusive em regimes políticos, como no caso das ditaduras. Na introdução de seu livro Teoria queer: um a aprendizado pelas diferenças, Miskolci (2017) relata sua experiência, ainda adolescente, sob a presidência do general Figueiredo no Brasil:

Sob o regime ditatorial militar, vivia sob a sombra de uma ordem política e social que girava em torno de um poder eminentemente masculino. A masculinidade se confundia com a violência, em um jogo injusto e cruel para as meninas, mas também para os meninos que, como eu, não gostavam de futebol, tampouco queriam emular o comportamento dos adolescentes que, com 18 anos, adentravam na vida adulta vestidos em seus uniformes do serviço militar obrigatório. Foi nele que vi um de meus primos, antes amoroso, ser brutalizado até se tornar o que se compreendia como um homem de verdade: aquele que dominava as mulheres e desprezava as "bichas” (Miskolci, 2017, p. 10).

O Informe meteorológico ${ }^{2}$ que dá início às memórias de Camilo anuncia que o clima sufocante no qual a história será contada reflete as sensações de um período opressor vivido no país, mas também em sua família, sobretudo pela ocupação de seu pai: um médico supostamente ligado ao regime ditatorial. A obscuridade característica do momento político se faz presente na história: e tudo fica sob um manto de dúvidas e incertezas:

[...] Se tudo bate (há muitos carimbos oficiais, mas nunca procurei saber o fundo da verdade), papai foi o "doutor Pablo" que ajudava nos porões, mantendo os prisioneiros sobrevivos. Pode ser invenção do rancor dela. Na carta, mamãe diz que não sabia de onde

\footnotetext{
2 “INFORME METEOROLÓGICO A temperatura deste romance está sempre acima dos $31^{\circ} \mathrm{C}$. Umidade relativa do ar: jamais abaixo dos 59\%. Ventos: nunca ultrapassam os $6 \mathrm{~km} / \mathrm{h}$, em nenhuma direção. O mar está muito longe deste livro" (Heringer, 2016, p. 9).
} 
ou por que meu pai tinha resgatado Cosmim, mas ela achava que era o filho de uma de suas vítimas, talvez do sêmen estúpreo dele próprio. Por isso tinha dó, mas nem conseguia olhar para o menino direito etc. (Heringer, 2016, p. 37).

O regime da ditadura militar na década de 1970, período em que se passam as memórias de Camilo narradas no romance de Heringer (2016), marcará a vida da personagem desde a sua infância, fase esta que a personagem utiliza como metáfora para relatar como era viver, ainda que criança, sob o comando de um regime opressor:

Nós nem imaginávamos a crise que perturbava há meses o casamento dos pais. Nem sabíamos quem governava o país. Vivíamos sob a esquisita ditadura da infância: víamos sem enxergar, ouvíamos sem entender, falávamos e não éramos levados a sério. Mas fomos felizes durante o regime. O tecido de nossas vidinhas era escuro e nos escondia completamente, burca sem olhos (Heringer, 2016, p. 15).

É com a chegada de Cosme que o tecido da vida de Camilo começa a mudar, ou, como narra a personagem na sequência do trecho acima: "O primeiro rasgão se deu naquele dia." (Heringer, 2016, p. 15). Apesar de tê-lo odiado assim que Cosme chegou para morar com sua família, o sentimento mais se dava a parecer com ciúmes de filho que via outro garoto mais próximo de seu pai: “[...] e odiei o nome dele - 'O nome dele é Cosme', papai disse -, e odiei a camisa azul-bebê que ele estava usando (comprada por papai, certeza, e sua corrida desajeitada até as asas do meu pai, que o aninhou com aquela mãozada que tinha" (Heringer, 2016, p. 16). Mas não demorou muito para que o sentimento fosse transformado e Camilo passasse a amar Cosmim e, finalmente, pudesse sair de casa, descobrir a rua: "quando Cosmim me apresentou a rua (agora eu podia brincar lá fora, era homem-macho, sim), o Queím se agigantou tanto ao redor que o ar chegou a ficar rarefeito. Engasguei (era medo, sim), ele bateu delicadamente nas minhas costas: 'Tudo bem?'. 'Tudo.' 'A rua não morde'” (Heringer, 2016, p. 44-45). É nesse momento que Camilo também se dá conta da posição social que ocupa, embora ainda confuso: "Foi a primeira vez que percebi que vivia entre gente pobre. Talvez eu fosse pobre também?" (Heringer, 2016, p. 46). A resposta vem do contato com os demais garotos do bairro:

Não. Logo eles deixaram claro que eu era o diferente - diferente para-o-bem, não diferente para-o-que-pena (o que sempre foi mais comum). Eu era muito branco, tinha sandálias que não eram de borracha (mas de velcro!) e a minha casa tinha portão e muro, ninguém enxergava dentro dela. Papai dirigia um Corcel e a minha mãe ninguém nunca tinha visto. Só mulher rica vivia escondida daquele jeito. "Seu pai faz o quê?" "É médico" (Heringer, 2016, p. 46).

Das memórias de Camilo, percebe-se que outras marcas também se fazem presentes na constituição de sua subjetividade, entre elas, dos trechos acima citados, destacam-se as marcas de classe e as étnico-raciais. Mas cumpre observar que tais marcas não estão apartadas da sexualidade. De acordo com Louro (2018, p. 101), “a sexualidade não se constitui num campo externo a outros modos de diferença, como as de raça, etnicidade, nacionalidade, religião ou classe". O romance, nesse sentido, possibilita uma multiplicidade de caminhos para reflexão. De volta ao espaço da rua, onde também convergem todas essas marcas, é interessante observar que é justamente no ambiente longe de casa e da família que o menino começa a ter contato com uma vida marcadamente masculina. $\mathrm{Na}$ parte intitulada Fábrica da virilidade, que integra o terceiro volume da História da virilidade, Arnaud Baubérot (2013) destaca os bandos entre os últimos vestígios da virilidade tradicional, nos quais, descreve o autor:

fora da família o garoto encontra, através do contato com seus pares, grupos que participam ativamente de sua iniciação viril. [...] O bando se apresenta, portanto, como uma antítese do lar, universo feminino no qual o garoto é devolvido a sua meninice. Dentro dele exacerba-se determinada relação com a masculinidade feita da dureza, dos jogos de força ou de coragem, dos desafios e da autoafirmação (Baubérot, 2013, p. 195).

Tudo isso esteve ao alcance e foi vivido por Camilo durante o curto período em que, ao lado de Cosmim, frequentou as ruas do bairro do Queím com o bando. Contudo, foi nesse mesmo espaço e para estes mesmos garotos que Camilo e Cosmim apareceram de mãos dadas e, como para selar uma união, beijaram-se para as testemunhas: 
Chegamos os dois ao pé dos moleques (nenhuma menina). Ele [Cosme] apertou meus dedos com as duas mãos e me deu um beijo de pode beijar a noiva. Ficaram sem reação por muito tempo, as caras travadas [...]. Tinham a obrigação da raiva, do asco, da piada, mas ninguém queria começar. Olharam para nós. Não rimos. Encaramos. [...] Todos se entreolharam, adivinhando a possibilidade da porradaria generalizada. $O$ Baleião disse parou, caralha, parou! Depois, pra dizer qualquer coisa, o Nó fez um comentário sobre eu ser branco e ele [Cosmim] marrom, eu rico e ele pobre. Golpe do baú. E riu, porque também não podia só mudar de assunto e seguir em frente. Foi isso. Em poucas horas eles se recuperaram das porradas e se acostumaram com a ideia de que seus dois amiguinhos viraram namorados. [...] Não faziam piada, mas pararam de xingar e empurrar o Cosme. Durante duas semanas, eles respeitaram (Heringer, 2016, p. 97-100).

O amor entre Cosmim e Camilo, desde o primeiro beijo até o assassinato de Cosme durou exatamente quatorze dias, as mesmas duas semanas de respeito que tiveram dos garotos da rua. Assassinado com vinte e seis facadas no tórax, "Cosmim foi violado antes e depois de morrer. Descobriram na autópsia. O assassino teve a gentileza de vestir a cueca de volta no cadáver" (Heringer, 2016, p. 115). Embora nunca tenha sido identificado, o assassino de Cosme é revelado por Camilo: Adriano, marido de Paulina, empregada na casa de Camilo. O assassinato aconteceu após Adriano ver Cosme e Camilo na cama, na casa onde trabalhava a esposa. Desde então a vida de Camilo levou consigo a abertura não cerzível daquele primeiro rasgão e o brutal rompimento do primeiro amor:

E eu cresci mais triste que um pombo. Fiquei adulto irritado, imprestável e sujo. Meu pai repetia sempre que pombo é rato com asa, porque é cheio das doenças. Eu não tenho asa. Eu sou aquilo no qual ninguém quer pensar enquanto está almoçando. Este calor, este suor que nunca brota direito dos poros! O assassinato tomou domínio de mim para o resto da vida. Fui colonizado (Heringer, 2016, p. 114).

Fora da ordem heteronormativa, Cosme e Camilo encontravam-se sob o domínio da abjeção. O abjeto, contudo, para além da sexualidade, também tem os seus contornos no corpo físico de Camilo, mas se imprimiu mais fortemente naquele que, além de desviar-se da norma heterossexual, era negro, pobre e abrigado no lar que era de outra família: Cosme. Miskolci (2017) destaca, porém, que é via sexualidade que a abjeção se mostra maior, isso porque, nela se unem os "sentimentos mais profundos, em que a pessoa mais se sente em confronto com a ordem social" (2017, p. 44). Dessa forma, independentemente de a paixão se dar por uma pessoa do mesmo sexo ou do sexo oposto, "toda pessoa que está envolvida na questão da afetividade e do amor se vê necessariamente num particular, num pessoal, e aí qualquer espécie de norma social que venha mexer com isso acaba sendo violenta" (Miskolci, 2017, p. 44). A heteronormatividade, nesse sentindo, produz constantemente práticas simbólicas e concretas de violência e perpetua uma masculinidade que é tóxica, afastando da construção de subjetividades masculinas sentimentos de afeto, carinho, amor. O que se pode perceber no seguinte trecho descrito por Miskolci (2017, p. 10-11):

Um "homem de verdade", hoje percebo, era o que impunha seu poder aos outros e a si mesmo à custa de sua própria afetividade. Daí meu primo, desde o uso do uniforme, ter deixado de ser carinhoso para dotar expressões de afetividade que sempre terminavam em pequenas torturas, como se um abraço ou um carinho entre homens tivesse que resultar em uma luta, um soco ou um machucado. Ele não era exceção, antes a regra em uma época em que meninos eram submetidos a uma pedagogia da masculinidade até se tornarem adultos, alguns, como ele, para sempre traumatizados pela recusa da afetividade que lhes era imposta, por uma (de)formação que os tornava incapazes de compreender as mulheres como iguais, tampouco de confiar em outros homens como confidentes de seus temores ou dores.

São, pois, as práticas reiteradas de atos, de maneiras de ser e de agir, culturalmente construídas e impostas, como no caso da identidade masculina pautada na virilidade, que formam, modelam e tentam normalizar e enquadrar os sujeitos dentro de categorias determinadas de gênero. A repetição estilizada de atos, de acordo com Butler (2017, p. 242), é que institui o gênero, de modo que seu efeito é produzido pela "estilização do corpo e deve ser 
entendido, consequentemente, como a forma corriqueira pela qual os gestos, movimentos e estilos corporais de vários tipos constituem a ilusão de um eu permanente marcado pelo gênero" (Butler, 2017, p. 242). O caráter ilusório sobrevém dos desvios da norma, do que não se enquadra no normativo, ou ainda, daqueles que, mesmo dentro da norma, assumem posturas não normativas, transgredindo-a.

Retorna-se, então, à proposta da teoria queer, cujo "olhar mais atento [que proporciona] revela que a multiplicação de identidades determina um desafio vigoroso à ordem de gênero, que aprisionara os indivíduos à sua lógica binária e instituíra papéis sociais pré-definidos" (Lugarinho, 2012, p. 97). A partir da teoria queer, provocações como a de pensar a "heterossexualidade como algo opcional" (Miskolci, 2017, p. 14) podem ser colocadas em discussão para que não seja algo impensável ou mesmo inaceitável. Das memórias de Camilo, já na idade adulta, ele recorda que nada do que viveu com Cosmim foi de conhecimento do seu pai: "Nada disso chegou aos ouvidos do meu pai. Claro. Até onde eu sei, ele morreu achando que as mulheres é que não gostavam de mim" (Heringer, 2016, p. 101).

A heteronormatividade, como um dos focos da teoria queer, traz entre suas consequências a produção e manutenção de uma masculinidade tóxica, pautada em práticas simbólicas e concretas de violência que afetam, mais diretamente e de forma letal, uma quantidade assustadora de mulheres, de homossexuais, de lésbicas, de transexuais, mas também de homens que não se adequam a essa norma, aliando-se a uma política de proliferação de ódio. $O$ "estranhamento queer pode ser instigante para se pensar a cultura, a sociedade, para se pensar o próprio pensamento" (Louro, 2018, p. 101), para se pensar as vivências de amor e, com isso, resistir à heteronormatividade e combater a masculinidade tóxica.

Anos depois de ter saído do Queím, Camilo resolve voltar: "Depois de mais de trinta anos longe do Queím, voltei. Quero morrer aqui mesmo onde nasci. Todo mundo tem vontade de simetria" (Heringer, 2016, p. 18). É quando, então, reconhece o menino Renato, neto do assassino de Cosmim. Como que um garoto sem rumo, avulso - assim como Camilo na sua vida depois de Cosmim -, Renatinho começa a frequentar o apartamento de Camilo e demonstrar gestos afetuosos: gestos de criança que reconhecem o carinho de quem está por perto. Para Camilo, um retorno à ternura. A mudança de Renatinho para o seu apartamento é como "um sol dentro de casa", nas palavras do título que demarca a segunda parte do livro, narrada de forma onisciente. $\mathrm{O}$ sol de agora, contudo, não é mais o sol detestado por Camilo, como fora naquele tempo de calor sufocante, quase sem vento, de um período opressor, de morte com assassino não identificado, de olhos que nada viam, de bocas que nada falavam, mas de meninos que, mesmo em meio a tudo isso, saíram às ruas de mãos dadas, beijaram-se publicamente na frente dos outros meninos do bairro: beijaram-se e deram-se as mãos num espaço de virilidade tradicional. Amaram-se, sem precisar saber qual o gênero que heteronormativamente lhes correspondia.

Talvez o que mais se encontre na literatura sejam histórias de amor, a maioria com finais heteronormativamente felizes. Há quem diga que todas as histórias são de amor. São múltiplas as formas de experienciar o amor, de amar e ser amada/o - e talvez todas sejam ensaiadas e ensinadas culturalmente. $\mathrm{O}$ perigo está numa cultura construída à imagem e à semelhança dos sujeitos heterossexuais porque se faz excludente de tudo o que desse modelo desvia. O perigo está justamente nessa exclusão que desumaniza seres humanos, apaga-lhes a subjetividade, retira-lhes a existência. A resistência a essa violência desumanizadora também acontece em espaços onde outras histórias de amor podem ser vividas, como no espaço literário. Nesse caso, serão apenas histórias narradas, fora do que é real, dirão alguns, mas se o que pode ser imaginado também pode ser vivido, o que nos é contado pela ficção talvez já esteja acontecendo por aí.

Essa breve leitura de $O$ amor dos homens avulsos a partir de aportes teóricos da teoria queer permite perceber a possibilidade de resistência à normatividade de qualquer ordem, sobretudo à hegemonia da heterossexualidade compulsória, mesmo em um estado de imersão em regimes políticos opressores, cada vez mais presentes entre nós, ainda que ocupando a categoria de corpos abjetos, a "diversidade de potências de vida" (Preciado, 2011, p. 18) traz junto de si 
potências de amor e com elas resistência, numa (sobre)vivência em que Cosmins e Camilos e Renatinhos possam viver abraços de amor e abraços de amigo.

\section{Referências}

AMARAL, Ana Luísa (2017). "Arder a palavra e outros incêndios", de Ana Luísa Amaral. Porto, Portugal: ILCML. On-line. Disponível em: http://ilcml.com/arder-a-palavra-e-outros-incendios-de-ana-luisa-amaral/. Acesso em: 10 nov. 2019.

AMBRA, Pedro (2019). Do mito aos horizontes de desconstrução. Cult, São Paulo, ano 22, n. 242, p. 17-19, fev. (Dossiê Cartografias da masculinidade).

ANDRADE, Mario de (2013). Estâncias. In: ANDRADE, Mario de. Poesias completas Mario de Andrade: edição de texto apurado, anotada e acrescida de documentos por Tatiana Longo Figueiredo e Telê Ancona Lopez. Rio de Janeiro: Nova Fronteira. p. 431-432.

BAUBÉROT, Arnaud (2013). A fábrica da virilidade. In: CORBIN, Alan; COURTINE, Jean-Jacques; VIGARELLO, Georges (Dir.). História da virilidade: 3. A virilidade em crise?. Tradução de Noéli Correia de Mello Sobrinho e Thiago de Abreu e Lima Florêncio. Petrópolis, RJ: Vozes. p. 185-238.

BUTLER, Judith (2000). Corpos que pesam: sobre os limites discursivos do "sexo". In: LOURO, Guacira Lopes (Org.). O corpo educado: pedagogias da sexualidade. Tradução de Tomaz Tadeu da Silva. Belo Horizonte: Autêntica. p. 151-165.

BUTLER, Judith (2017). Problemas de gênero: feminismo e subversão da identidade. 15. ed. Tradução de Renato Aguiar. Rio de Janeiro: Civilização Brasileira.

CUNHA, Eduardo Leal (2019). A normalização das homossexualidades e os destinos do masculino. Cult, São Paulo, ano 22, n. 242, p. 25-27, fev. (Dossiê Cartografias da masculinidade).

FOUCAULT. Michel (2010). Os anormais: curso no Collège de France (1974-1975). Tradução de Eduardo Brandão. São Paulo: WMF Martins Fontes. (Coleção Obras de Michel Foucault).

HERINGER, Victor (2016). O amor dos homens avulsos. São Paulo: Companhia das Letras.

LAURETIS, Teresa de (1994). A tecnologia do gênero. In: HOLLANDA, Heloísa Buarque de. Tendências e impasses: o feminismo como crítica da cultura. Rio de Janeiro: Rocco.

LOURO, Guacira Lopes (2018). Um corpo estranho: ensaios sobre sexualidade e teoria queer. Belo Horizonte: Autêntica. (Argos).

LUGARINHO, Mário César (2012). Agenciamentos de gênero nas literaturas africanas de língua portuguesa: um caso caboverdiano. In: LUGARINHO, Mário César (Org.). Do inefável ao afável: ensaios sobre sexualidade, gênero e estudos queer. Manaus: EUA Edições. p. 75-86.

MISKOLCI, Richard (2017). Teoria queer: um aprendizado pelas diferenças. 3. ed. Belo Horizonte: Autêntica Editora; UFOP. (Cadernos da Diversidade, 6).

PRECIADO, Paul B. (2011) Multidões queer: notas para uma política dos "anormais". Revista Estudos Feministas, Florianópolis, v. 19, n. 1, p. 11, jan. Disponível em: https:// bit.ly/2ZjDKGQ. Acesso em: 10 nov. 2019.

RICH, Adrienne (2010). Heterossexualidade compulsória e existência lésbica. Tradução de Carlos Guilherme do Valle. Bagoas, UFRN, n. 5, p. 17-44. Título original: Compulsory heterosexuality and lesbian existence. Disponível em: http://www.cchla.ufrn.br/bagoas/v04n05art01_rich.pdf. Acesso em: 10 nov. 2019.

SCOTT, Joan W. (1999). Experiência. In: SILVA, Alcione Leite da; LAGO, Mara Coelho de Souza; RAMOS, Tânia Regina Oliveira (Org.). Falas de gênero: teorias, análises, leituras. Florianópolis: Ed. Mulheres. p. 21-55.

SCOTT, Joan W (1998). A invisibilidade da experiência. Tradução de Lúcia Haddad. Projeto História, São Paulo, v. 16, set. Disponível em: https://revistas.pucsp.br/revph/article/view/11183. Acesso em: 20 nov. 2019.

SILVA, Leandro Soares da (2019). Victor Heringer - O amor dos homens avulsos. Estudos de Literatura Brasileira Contemporânea, Brasília, n. 56, e5624. Disponível em: https:// bit.ly/3bHBPAV. Acesso em: 8 nov. 2019.

SPARGO, Tamsin (2017). Foucault e a teoria queer: seguido de Ágape e êxtase: orientações pós-seculares. Tradução de Heci Regina Candiani. Belo Horizonte: Autêntica. (Argos, 2). 